\title{
O Processo Saúde-Doença e a Dependência Química: Interfaces e Evolução
}

\author{
Elisângela Maria Machado Pratta ${ }^{1}$ \\ Universidade Camilo Castelo Branco \\ Manoel Antonio dos Santos \\ Universidade de São Paulo
}

\begin{abstract}
RESUMO - O uso de drogas atualmente é considerado um grave e complexo problema de saúde pública. Falar sobre drogadição é discutir o processo saúde/doença, considerando-se os modelos que contribuem para a compreensão do fenômeno no momento atual e das estratégias de intervenção estabelecidas. Discutir a dependência química hoje exige uma reflexão sobre como a droga foi encarada ao longo da história, tendo em vista as questões de saúde/doença e os paradigmas hegemônicos em cada momento. Este estudo visa: a) mostrar as bases teórico-conceituais de três eixos (saúde, doença e dependência química) e suas interseções; b) propiciar uma reflexão crítica sobre a questão da promoção da saúde frente à dependência de drogas, de acordo com o modelo biopsicossocial presente na atualidade. Esse modelo considera o ser humano integral, dotado de subjetividade, de saberes e fazeres próprios, ativo no processo saúde/doença, ressaltando a necessidade de rompimento com o modelo cartesiano ainda predominante na saúde.
\end{abstract}

Palavras-chave: saúde pública; doença; drogadição; substâncias psicoativas; dependência química.

\section{The Health-Illness Process and the Chemical Dependence: Interfaces and Evolution}

\begin{abstract}
The drug addiction today is considered a complex and a serious Public Health problem. The discussion about drug addiction concerns the health/illness process, considering the models that contribute to the comprehension of this phenomenon at the current moment and to the established intervention strategies. Discussing the drug addiction today demands a reflection on how drug was faced throughout history, based on the health/illness issues and the hemogenic paradigms in each historical moment. This study intends to: a) show the theoretical-conceptual basis of three axes (health, illness and chemical dependence) and their intersections; b) activate a critical reflection about the health promotion issue in the context of chemical dependence, according to the biopsychossocial model currently present. This model considers the human being as a whole, gifted of subjectivity, knowledge and own tasks, active on the health/illness process, emphasizing the necessity of breaking the Cartesian model still dominant at health studies.
\end{abstract}

Keywords: public health; illness; drug addiction; psychoactive substances; chemical dependence.

A dependência química na atualidade corresponde a um fenômeno amplamente divulgado e discutido, uma vez que o uso abusivo de substâncias psicoativas tornou-se um grave problema social e de saúde pública em nossa realidade. Entretanto, falar sobre o uso de drogas, particularmente sobre a dependência química, traz à tona questões relacionadas diretamente ao campo da saúde, o que implica na necessidade de realizar uma reflexão sobre esse fenômeno no âmbito das concepções sobre saúde e doença, vigentes ao longo da história do homem, bem como no momento atual. Isso porque temas como saúde, doença e drogas sempre estiveram presentes ao longo da história da humanidade, embora cada período apresente uma maneira particular de encarar e lidar com esses fenômenos, de acordo com os conhecimentos e interesses de cada época.

No que diz respeito ao uso de substâncias psicoativas, ao contrário do que se pensa, esse não é um evento novo no repertório humano (Toscano Jr., 2001), e sim uma prática

1 Endereço para correspondência: Rua XV de Novembro, 2378, Apto 12, Edifício José Alfredo, Centro. São Carlos, SP. CEP 13560-241. E-mail: emmppsic@scl.terra.com.br. milenar e universal, não sendo, portanto, um fenômeno exclusivo da época em que vivemos. Pode-se dizer, então, que a história da dependência de drogas se confunde com a própria história da humanidade (Carranza \& Pedrão, 2005), ou seja, o consumo de drogas sempre existiu ao longo dos tempos, desde as épocas mais antigas e em todas as culturas e religiões, com finalidades específicas. Isso porque, o homem sempre buscou, através dos tempos, maneiras de aumentar o seu prazer e diminuir o seu sofrimento (Martins \& Corrêa, 2004).

Entretanto, é importante pontuar que os hábitos e costumes de cada sociedade é que direcionavam o uso de drogas em cerimônias coletivas, rituais e festas, sendo que, geralmente, esse consumo estava restrito a pequenos grupos, fato esse que apresentou grande alteração no momento atual, pois hoje se verifica o uso dessas substâncias em qualquer circunstância e por pessoas de diferentes grupos e realidades.

Por outro lado, em relação à saúde e à doença, estas também despertaram a atenção do homem desde a Antiguidade, uma vez que estão diretamente relacionadas a questões que fazem parte da condição humana, como é o caso da reflexão 
sobre a vida e a morte, o prazer e a dor, sofrimento e o alívio, trazendo à tona, a inerente fragilidade do homem.

Analisando a evolução histórica do ser humano é possível verificar que cada época apresenta uma maneira particular de lidar com esses elementos, ou seja, com a saúde e a doença. No caso das doenças, é possível notar que as concepções que se apresentaram ao longo da história caminharam do sobrenatural para o natural e, consequentemente, para o social (Ornellas, 1999). Ao longo dos tempos nota-se uma mudança de foco no que se refere à compreensão e valorização destes eixos (saúde - doença), partindo de um paradigma que tem por finalidade a manutenção da saúde até chegar a um novo paradigma que apresenta como centro a questão da doença. Esse último permaneceu durante muito tempo como modelo adequado para compreender questões referentes à saúde e à doença, e hoje passa por um período de crise.

Assim, tomando-se por base o referencial acima mencionado, o presente estudo visa mostrar os alicerces teóricosconceituais de três eixos — saúde, doença e uso de substâncias psicoativas - e suas interseções, de forma a ativar e manter uma reflexão crítica das ideias e valores relacionados aos mesmos. Para tanto, três objetivos específicos permeiam esta reflexão. São eles: (a) discutir as mudanças nas concepções sobre saúde e doença e suas implicações no que se refere ao uso de substâncias psicoativas, considerando-se os principais momentos históricos; (b) refletir sobre as influências do modelo biomédico, hegemônico na área da saúde, na discussão e no atendimento dispensado ao usuário de drogas a partir do século XX; (c) abordar a questão da dependência química e do tratamento da mesma, tendo por base o modelo de produção social da saúde, enfatizando a importância da promoção e da prevenção nesse contexto.

\section{O Processo Saúde-Doença e o Uso de Drogas: Uma Visão Histórica}

Discutir questões ligadas aos conceitos, à compreensão e à elaboração de modos de encarar a saúde, a doença e os cuidados, ao longo do contexto histórico, coloca em evidência “a questão da evolução histórica da [própria] prática médica como instituição que detém a legitimidade hegemônica do domínio desse cuidado e dos saberes relativos à doença e à saúde" (Ornellas, 1999, p. 20). Assim, seguindo os trâmites da história em seus principais momentos, é necessário começar a falar sobre saúde e doença retomando reflexões e conhecimentos que foram produzidos na Antiguidade.

Segundo Sevalho (1993), as primeiras representações de saúde e doença estavam ligadas a uma questão mágica, como no caso das concepções dos antigos povos da Mesopotâmia, uma vez que para eles as doenças eram provocadas por influências de entidades sobrenaturais, com as quais o ser humano não podia competir. Posteriormente, a doença passou a ser explicada no âmbito das crenças religiosas, sendo, portanto, determinação dos deuses. Essa visão começou a mudar a partir dos conhecimentos desenvolvidos pelos egípcios, os quais evidenciaram uma naturalização das doenças, aliada às crenças sobrenaturais, religiosas e mágicas que os mesmos possuíam.
Os gregos, um povo considerado avançado para seu momento histórico e que apresentava uma característica particular, a preocupação em compreender a natureza do homem, produziram um rico conhecimento mitológico e filosófico, os quais embasaram as explicações sobre saúde e doença nessa época. Assim, em um primeiro momento, as explicações para as doenças entre os gregos tinham uma fundamentação religiosa.

Nesse período, existia no ideário popular a concepção de que o sobrenatural (no caso, os deuses) era responsável pela manifestação das doenças, ou seja, existia a ideia de sacralização das doenças, uma vez que o homem tinha por costume curvar-se às divindades e se submeter aos mais diversos tipos de sacrifícios com a finalidade de livrar-se de alguma enfermidade, do castigo e das impurezas (Toscano Jr., 2001).

Essa visão sofreu mudanças a partir das ideias de Hipócrates, o qual foi o primeiro a formular um conceito de causas naturais para os eventos presentes em nosso mundo (Sevalho, 1993). Segundo sua concepção, o homem era constituído de quatro humores corporais sendo estes o sangue, a bílis amarela, a bílis negra e a fleuma, os quais eram oriundos de quatro qualidades específicas da natureza: calor, frio, umidade e aridez. Dentro dessa visão, a saúde resultaria da harmonia, do equilíbrio entre esses quatro humores e, por outro lado, a doença teria origem no excesso ou na escassez de um deles ou na falta de mistura dos mesmos no organismo, sendo a cura ligada à busca do equilíbrio (Cairus \& Ribeiro, 2005). Assim, a medicina de Hipócrates apresentava uma preocupação clara com a doença individual e com a forma de curá-la, bem como com a manutenção da saúde.

Além disso, a emergência da escola hipocrática, considerando a doença e a cura como resultados de processos naturais (MacRae, 2001; Toscano Jr., 2001), levou a nova medicina a receitar o pharmakón (palavra que significa remédio ou veneno) para o tratamento das enfermidades em busca da cura (Toscano Jr., 2001).

Assim, para os gregos, que empregavam vários tipos de drogas, a ação dessas era vista de maneira relativa, pois uma determinada substância poderia ser utilizada, simultaneamente, como remédio ou veneno, dependendo de sua dosagem. Isso porque era essa dosagem que determinava o efeito curativo de uma determinada substância utilizada e o envenenamento provocado pela mesma (MacRae, 2001; Toscano Jr., 2001).

Os romanos, que sofreram grandes influências dos gregos, também compartilhavam dessa posição, encarando as drogas como basicamente neutras, isto é, seus efeitos, sejam estes positivos ou negativos, dependiam da dosagem e da maneira de uso das mesmas (MacRae, 2001; Toscano Jr., 2001).

No final da Antiguidade e durante toda a Idade Média (século $\mathrm{V}$ ao XV) retoma-se a concepção de doença como algo sagrado, provocado pelo sobrenatural, embora a mesma também continuasse sendo encarada como a manifestação de alterações globais do organismo na sua relação com o meio físico e social (Queiroz, 1986). Pode-se dizer, assim, que até esse momento, de uma forma ou de outra, a maioria dos terapeutas levava em consideração a interação corpo e alma, buscando tratar seus pacientes a partir do meio social e espiritual no qual os mesmos se encontravam (Capra, 1982). 
Nesse período, os hospitais criados no Ocidente eram caracterizados como casas de assistências e abrigos, bem como funcionavam como instrumentos de exclusão ao isolar os doentes do restante da população (Sevalho, 1993).

Em relação ao uso de drogas, durante a Idade Média, é necessário pontuar que a Igreja Católica, que possuía um grande poder nesse período, tanto em termos religiosos quanto em termos econômicos e sociais, passou a condenar o uso das plantas consideradas como "diabólicas", as quais eram vistas como sinônimo de feitiçaria (Toscano Jr., 2001). Essas plantas passaram a ser estigmatizadas, gerando perseguições tão intensas que, no século $\mathrm{X}$, o emprego de drogas para fins terapêuticos tornou-se sinônimo de heresia, uma vez que o sofrimento era concebido como uma maneira de aproximação a Deus (MacRae, 2001).

É importante esclarecer que durante a Idade Média a única droga permitida pelo Cristianismo era o álcool, mais precisamente o vinho, o qual até hoje é considerado um elemento relevante dentro dessa religião, uma vez que simboliza o sangue de Jesus Cristo (Toscano Jr., 2001). O uso de qualquer outro tipo de droga, como unguentos e poções, era condenado pela Igreja Católica e os indivíduos que os utilizavam eram punidos com torturas e morte pelos tribunais da Inquisição (MacRae, 2001).

Apesar dessas restrições e das perseguições constantes realizadas pela Igreja Católica, a Idade Média conseguiu acumular "todo um saber herbário, alquímico e secreto, bem como de uma prática popular sobre as plantas" (Toscano Jr., 2001).

No final da Idade Média, a Europa é assolada pela peste negra — peste bubônica —, que provocou uma grande mudança na realidade da época, evidenciando o medo do sofrimento e da morte. Nesse período, o pensamento da morte tornou-se evidente. Os princípios da medicina galênica não conseguiram dar conta dessa nova vivência, o que levou Sydenhan a apoiar-se nas obras dos empiristas, “especialmente Bacon e Locke, e [iniciar] um novo modo de conceber a doença, através de dois elementos importantes: o empirismo clínico, que se apóia na observação, e uma nova classificação das doenças, agudas e crônicas, ainda hoje utilizada" (Ornellas, 1999, p. 20).

A partir desse momento, essa nova forma de conceber a doença, associada a um conjunto de outros fatores da época, levou à emergência de um novo olhar sobre a questão da saúde e doença e da relação entre as mesmas, bem como no que diz respeito ao uso de drogas.

Desta forma, com o Renascimento - final do século XV ao início do XVI - , que levou à queda gradativa do poder e da influência exercidos pela Igreja Católica em todos os âmbitos da sociedade, é possível notar grandes transformações na realidade da época. Por exemplo, a possibilidade de um contato mais íntimo com as culturas orientais, em que antigos conhecimentos farmacológicos haviam sobrevivido melhor, possibilitou uma retomada gradual do uso de drogas (MacRae, 2001).

Por outro lado, nesse período ocorreu um grande avanço científico, evidenciando-se a necessidade de laicização do saber, o que levou ao nascimento da ciência moderna. A ciência, que durante toda a Idade Média, sofreu um processo de estagnação, retomou aqui seu papel, com uma nova roupa- gem. A ciência moderna passou a exigir a sistematização do conhecimento, seguindo para isso normas e regras específicas para a produção do mesmo, o que fez com que a observação, a descrição e a classificação delimitassem o paradigma da mesma. Com isso, as ideias da experiência e da intervenção incorporaram-se ao pensamento moderno (Ornellas, 1999).

Frente a esse contexto, a partir do século XVII, a evolução da medicina acompanhou de perto o desenvolvimento ocorrido na ciência, principalmente na biologia, a qual apresentava uma concepção mecanicista da vida, concepção esta que passou a dominar, consequentemente, a atuação dos médicos em relação à saúde e à doença (Capra, 1982).

Tomando como base esse paradigma, Descartes (século XVII) desenvolveu o conceito de dualismo mente e corpo, passando a encarar o corpo como uma máquina, o qual poderia ser explorado e estudado (paradigma mecanicista). Essa visão quebrou a concepção predominante na Idade Média, do corpo como algo sagrado e inviolável, por ser considerado o "depósito" da alma. Consequentemente, essa visão criou uma concepção de doença como um mau funcionamento das "peças" da máquina humana, o qual poderia ser reparado por meio de uma intervenção específica da medicina, desde que esta desenvolvesse conhecimentos pontuais das leis que regem o funcionamento dessa máquina (Ornellas, 1999; Sevalho, 1993), e uma concepção de morte como a paralisação total da mesma (Capra, 1982).

A função do médico, a partir de então, seria a de intervir "física ou quimicamente, para consertar o defeito no funcionamento de um mecanismo enguiçado" (Capra, 1982, p. 116), ou seja, como um bom mecânico, devendo, portanto, reparar o que não estava adequado.

Nota-se, assim, uma mudança epistemológica na medicina, a qual passou de uma arte de curar os indivíduos, portanto, uma prática, para uma disciplina das doenças (o saber componente da prática é organizado e sistematizado segundo determinados padrões) (Ornellas, 1999). Além disso, a divisão entre corpo e mente, proposta por Descartes, levou os médicos a direcionarem sua atenção para a máquina corporal, para o biológico, deixando de lado aspectos psicológicos, sociais e ambientais da doença (Capra, 1982), o que demonstra uma visão reducionista da doença. Teve início, assim, o modelo biomédico, que se constituiu no alicerce conceitual da moderna medicina científica, permanecendo na área da saúde aproximadamente quatro séculos após Descartes.

No âmbito dessa nova concepção, ganha força a interpretação do sinal físico, ou seja, do sintoma, sendo desenvolvido todo um sistema de classificação das doenças de uma forma ordenada e sistematizada. A doença passou a ser identificada a partir de uma realidade concreta e começou a ser localizada no corpo, sendo evidenciada a partir da lesão anatômica. Buscava-se, portanto, a relação entre lesão e sintomas dentro de uma perspectiva anatomopatológica (Capra, 1982; Ornellas, 1999). Procurava-se, no doente ou no laboratório, evidências que apontassem para uma patologia específica, ocorrendo uma objetivação do corpo, o qual se tornou interessante por ser a sede das doenças, e por outro lado, uma objetivação das próprias doenças, que se transformaram em entidades patológicas a serem exploradas e compreendidas (Ornellas, 1999). 
Dentro desse contexto, a teoria da medicina assumiu a concepção biológica da doença, passando a ser a teoria das doenças. A saúde, a partir desse foco, passou a ser encarada como a ausência de doenças e o processo de cura, como a eliminação dos sintomas evidenciados. Assim, o médico, em sua atuação, era dotado de cada vez mais poder e controle sobre a questão da doença e o seu tratamento, uma vez que passou a ter um saber e uma prática socialmente valorizados.

Segundo Queiroz (1986) a partir da Revolução Industrial (século XVIII), identificou-se uma "ruptura fundamental entre saúde e medicina, com uma hegemonia flagrante desta última. Esta ruptura veio acompanhada da [cisão] entre corpo e mente, eu e outro, pessoa e contexto, relações econômicas e comunitárias dentro de um mundo em intenso processo de burocratização e desencanto" (p.311). Destaca-se, ainda, que nas discussões sobre essa questão, os graves problemas sociais do início do capitalismo industrial (jornada de trabalho, urbanização, pobreza etc) em nenhum momento eram relacionados aos problemas de saúde vivenciados na época (Sevalho, 1993).

No que diz respeito ao uso de drogas, no decorrer do século XVIII, ocorreu uma diminuição na perseguição aos indivíduos considerados hereges, fato que propiciou uma volta do uso médico e lúdico das drogas (MacRae, 2001), ou seja, os próprios avanços científicos começaram a apontar a necessidade de se explorar a questão medicamentosa quando se discute a questão da doença dentro dos parâmetros em voga.

No início do século XIX desenvolveu-se a filosofia positiva, a qual teve um impacto direto no que diz respeito ao método científico ao ressaltar que todo e qualquer fenômeno deve ser explicado de uma forma objetiva, experimental. Nesse sentido, segundo Ornellas (1999), todo conhecimento produzido deve ser submetido ao que o Positivismo denominava de princípio da neutralidade do sujeito. Esse princípio levou a uma nova concepção de saúde e doença, uma vez que a medicina incorporou o conceito de função, desenvolvendo, a partir desse, a visão de saúde como um processo.

Também no início desse mesmo século, cientistas conseguiram isolar os princípios psicoativos de inúmeras plantas, passando a produzir determinados fármacos como a morfina, a codeína, a cafeína, a cocaína, os barbitúricos entre outros (MacRae, 2001; Toscano Jr., 2001). MacRae acrescenta, ainda, que foi desenvolvido também nesse período, o uso anestésico do éter, do clorofórmio e do óxido nitroso.

Destaca-se, ainda, que no século XIX houve o surgimento da Psiquiatria, a qual foi considerada como um ramo secundário no âmbito da medicina. A Psiquiatria incorporou o modelo biomédico vigente, procurando discutir a questão dos problemas mentais a partir da descoberta de causas orgânicas, ou seja, da busca da lesão, no caso, da lesão cerebral (Capra, 1982). O tratamento oferecido, na primeira metade do século $\mathrm{XX}$, era advindo desse modelo com ênfase no biológico.

Como a Psiquiatria seguiu a visão positivista predominante na época, a mesma contribuiu para encobrir valores e poderes presentes nesse cenário, como o caso da exclusão e morte social, uma vez que o paciente era retirado do convívio social e encarcerado, perdendo muitas vezes seus vínculos e sua própria identidade. Houve uma eclosão de hospitais psiquiátricos nesse período. Os mesmos atendiam os mais diversos tipos de problemática relacionados ao campo da saúde mental ou de pessoas que deveriam ser retiradas do convívio social, segundo os interesses vigentes na época (mendigos, leprosos, tuberculosos, portadores de sífilis, usuários de drogas etc).

Assim, a partir do século XIX a moderna medicina científica passou a apresentar um grande avanço, que teve início a partir dos grandes progressos efetuados na biologia. Dentre esses, pode-se mencionar o rápido desenvolvimento na compreensão dos processos fisiológicos, levando médicos e biólogos a se preocuparem com entidades cada vez menores, como por exemplo, aquelas de interesse da biologia celular e da teoria microbiana da doença (Capra, 1982). Esses conhecimentos deram à medicina um status diferenciado, conferindo-lhe um poder específico para controlar as doenças e uma visão individualista em relação ao objeto da saúde, ou seja, o foco de interesse passou a ser cada vez mais o indivíduo e não a população (Queiroz, 1986).

Segundo Capra (1982), os grandes avanços da biologia durante o século XIX foram acompanhados pela grande evolução na tecnologia médica. Por outro lado, os conhecimentos produzidos no século XIX foram aplicados de maneira diferenciada no século $\mathrm{XX}$, gerando o desenvolvimento de uma série de medicamentos e vacinas para o combate de doenças infecciosas, e descobertas importantes como a penicilina em 1928 e a produção de medicamentos psicoativos a partir da década de 50.

Esse desenvolvimento tecnológico e científico embasado no modo de produção capitalista vigente no final do século XIX pode ser caracterizado como um dos pontos que contribuíram para a tendência à especialização médica, que teve seu apogeu no século XX. Nesse século, a visão reducionista permaneceu na ciência biomédica, atingindo direta ou indiretamente todas as profissões da área de saúde e orientando a formação e atuação das mesmas.

\section{Saúde e Doença no Século XX: Mudança de Paradigmas}

No século XX, falar sobre saúde e doença era tomar como referencial o modelo biomédico. Isso porque o biologismo e o mecanicismo predominantes no modelo biomédico, bem como a acentuada especialização e tecnificação existentes, apresentaram impactos diretos no que diz respeito à compreensão do processo saúde-doença e à prática realizada junto ao paciente.

Nesse contexto, a concepção reducionista de doença resume a mesma ao aspecto biológico, deixando de considerar outros elementos relevantes que podem interferir na mesma; a especialização, por sua vez, leva a uma fragmentação do corpo, no qual cada parte deve ser cuidada de acordo com um conjunto de saberes de domínio de especialistas. Esses aspectos apresentaram implicações diretas na atuação do profissional com o paciente, o qual deixou de ser encarado pelo profissional de saúde em sua totalidade, sendo apenas sinônimo de um sintoma que apresenta ligação com uma doença específica. A doença, então, passou a ser o foco de interesse do profissional, como se fosse, segundo Backes, Lunardi e Lunardi Fiho (2006), desconectada do ser que a abriga e no qual a mesma se desenvolve. 
Desta forma, a doença enquanto foco de interesse, passou a ser dotada de objetividade, cuja causa era orgânica. Assim, o processo de adoecer estava reduzido ao biológico (visão reducionista), enquanto que a saúde era diretamente associada ao conhecimento disponível sobre a doença, ou seja, saúde era igual à ausência de doenças.

Essa relação estabelecida entre saúde e doença orientou toda a produção de conhecimentos e a prática médica nesse período, particularmente no que diz respeito ao tratamento oferecido ao paciente, além de estar coerente e reforçar o modelo produtivo e econômico da época. Esse contexto de certa forma levou a uma desumanização do homem na sociedade, não coincidindo diretamente, segundo Queiroz (1986), com as necessidades reais de saúde de uma população. Essa desumanização apareceu na sociedade, bem como nas práticas relacionadas ao processo saúde/doença.

Assim, as concepções vigentes sobre saúde e doença ofereceram um aparato que justificava e, de certa forma, impunha a necessidade de apagar a subjetividade existente no relacionamento entre profissional de saúde e paciente, evidenciando a racionalização, o que desvitalizava o próprio tratamento.

Esses aspectos ficam claros quando se coloca em pauta a questão da drogadição. O uso de álcool, por exemplo, vem desde a pré-história até a atualidade. Porém, o mesmo somente começou a aparecer na literatura como uma condição clínica, a partir dos séculos XVIII e XIX. Um dos motivos para isso diz respeito à urbanização decorrente da Revolução Industrial, a qual possibilitou que os médicos observassem mais os pacientes com consumo excessivo de álcool, produzindo os primeiros textos referentes aos problemas de saúde advindos do uso de bebidas alcoólicas.

Assim, pode-se dizer que a droga, como qualquer outro elemento presente na sociedade, segue a evolução das culturas, ou seja, os padrões, a frequência de utilização e os tipos de drogas consumidos mudam de uma época para outra de acordo com as condições sócio-culturais existentes. O que diferencia o uso das drogas no passado e o uso atual, é que este deixou de ser um elemento de integração, um fator de coesão social e emocional da população, passando a constituir-se num elemento de doença social, de desintegração (Bucher, 1992). Isso passou a ocorrer principalmente a partir da segunda metade do século XX, tendo contribuído diretamente para a desintegração do tecido social e para o aniquilamento da subjetividade em um mundo profundamente alienado.

Como a sociedade cada vez mais "coisifica" o homem, encarando-o como uma máquina, desumanizando-o, acaba deixando de lado valores humanos e afetivos importantes. Assim, "a drogadição não é mais do que uma das consequências da alienação histórico-social, política e econômica, através da qual se manifesta a dramática dissociação em que vivemos" (Kalina \& cols., 1999, p. 88). Ela é um sintoma da crise que atravessamos, decorrentes de uma gama de fatores incluídos na dimensão familiar, social e individual (Kalina \& cols., 1999), bem como das rápidas e consistentes mudanças no modo de organização das sociedades industrializadas (Toscano Jr., 2001). Essas transformações levaram a um modo de vida racional, materialista e normatizador, no qual o uso de drogas assumiu a forma de evasão, de contestação e/ou transgressão.
Além disso, no que diz respeito ao tratamento dos usuários de drogas, é necessário ressaltar que o mesmo tinha por base, no final do século XIX e primeira metade do século $\mathrm{XX}$, o modelo biomédico, estando diretamente ligado à assistência psiquiátrica. Os indivíduos que apresentassem problemas com álcool ou outras drogas eram encaminhados para instituições psiquiátricas com a finalidade primordial de retirá-los do convívio social e promover o abandono do uso, utilizando, para tanto, as mesmas técnicas empregadas com outros internos.

Sendo assim, segundo Ferreira e Luis (2004), a assistência ao uso de drogas, vinculada à assistência psiquiátrica, traz consigo a questão da violação dos direitos humanos, além do problema da má qualidade dos serviços prestados aos usuários, pois tem como base o modelo hospitalocêntrico.

Entretanto, apesar da predominância do modelo biomédico em todas as áreas da saúde, ao longo do século XX algumas contribuições foram significativas para gerar uma nova reflexão sobre a questão da saúde em si. Segundo Rezende (1986), a Organização Mundial da Saúde (OMS) propôs, em sua Carta Magna de 7 de abril de 1948, um conceito de saúde diferenciado, o qual constituiu um passo importante na compreensão desse fenômeno, apesar das restrições e controvérsias que o mesmo apresentava e ainda apresenta.

Para a OMS, saúde corresponde a um estado de completo bem estar físico, mental e social, e não apenas a mera ausência de moléstia ou doenças. Esse conceito, apesar de ser um pouco mais abrangente, torna-se, segundo alguns críticos, utópico e muitas vezes inatingível. "A utopia sustenta-se no termo bem-estar, definido como o estado de perfeita satisfação física ou moral. Aqui, o perfeito escapa por meio das possibilidades e imperfeições humanas, inviabilizando a conquista plena da satisfação" (Rosa, Cavicchioli \& Bretãs, 2005, p. 579).

Dessa forma, os aspectos acima relatados, abordando a questão da prática médica, a definição de saúde proposta pela OMS, associados a outros fatores, como mudanças demográficas e epidemiológicas, excessiva medicalização, desproporção crescente entre custo (como investimentos em hospitais, serviços, equipamentos etc) e eficácia (melhoria real na qualidade de vida da população), inacessibilidade do serviço, incorporação tecnológica descontrolada, urbanização, além de falhas desse modelo em explicar de uma forma abrangente os conceitos de saúde e doença, levaram ao questionamento do modelo biomédico como algo prioritário e imutável no contexto de saúde, a partir da segunda metade do século XX.

Isso porque, a partir desses fatores, percebeu-se que falar sobre saúde não é apenas contrapô-la à questão da doença, uma vez que saúde é algo mais amplo e complexo, que não depende única e exclusivamente de uma questão biológica. Quando se discute o binômio saúde/doença, é importante que esses fenômenos sejam encarados como processos, como algo dinâmico que se manifesta em qualquer ambiente sob a presença de diversos fatores inerentes à própria condição humana.

Portanto, tornou-se inegável a relação que existe entre os fenômenos saúde/doença e os fatores psicológicos, sociais, políticos, econômicos e ambientais, uma vez que condições inadequadas do meio exercem influência direta na possibili- 
dade de um indivíduo manter a saúde (Rosa, Cavicchioli \& Brêtas, 2005). Assim, o processo saúde/doença está diretamente relacionado à própria complexidade e singularidade do viver do ser humano, sendo determinado, portanto, não por intervenção médica, mas sim por comportamentos, alimentação, pela natureza do meio ambiente (Capra, 1982).

Surge, assim, a necessidade de se adotar uma perspectiva abrangente e dinâmica, levando à compreensão do processo saúde/doença como sendo um fenômeno histórico e multideterminado. Propõe-se, consequentemente o modelo biopsicossocial, o qual traz a ideia de integração, considerando saúde uma produção social, ou seja, como algo que tem relação com o biológico, mas que depende de uma série de outros determinantes sociais que estão implicados na vida de cada ser humano, como cultura, lazer, transporte, alimentação, educação, trabalho, saneamento básico entre outros. Esses determinantes são coerentes com uma discussão sobre melhoria na qualidade de vida, encarando a própria saúde como expressão dessa qualidade (Mendes, 1996).

A saúde passou a ser encarada como um momento, no processo saúde/doença, em permanente transformação (Mendes, 1996), sendo um fenômeno multidimensional. Tornou-se importante uma compreensão holística do processo saúde/ doença. Esse novo paradigma teve implicações diretas nas reflexões efetuadas sobre o binômio saúde/doença, bem como na prática exercida pelo profissional de saúde.

Dentro dessa nova visão, o profissional precisou rever o seu posicionamento frente ao paciente, passando a desenvolver uma maior sensibilidade frente ao sofrimento do outro. Além disso, segundo Caprara (2003), o paciente passou a não ser mais encarado apenas como um objeto para a intervenção médica, e sim como um sujeito ativo, integral, autêntico, com necessidades e valores, que vive, reflete e transforma o encontro clínico juntamente com o médico. Isso porque, segundo Ayres (2001), nesse encontro estão presentes duas subjetividades, o que implica em relação, em intersubjetividade, em mudança, em construção. Assim, sem desconsiderar a relevância da prática médica, entender o processo saúde/doença na atualidade exige a consideração de questões subjetivas, ou seja, a subjetividade volta à cena (Queiroz, 2003).

\section{A questão da dependência química no modelo psicossocial de saúde}

O consumo de substâncias psicoativas cresceu assustadoramente a partir da segunda metade do século XX, configurando-se nas últimas décadas desse século como um fenômeno de massa e como uma questão de saúde pública. Sendo assim, em função da complexidade desse fenômeno na atualidade, a dependência química é um problema que vem recebendo crescente atenção, mobilizando tanto o sistema de saúde (Aguilar \& Pillon, 2005; Canoletti \& Soares, 2005; Martins \& Corrêa, 2004) quanto a sociedade de uma forma geral. Além disso, tal questão está ganhando crescente visibilidade, uma vez que discussões sobre a temática estão presentes em diversos meios de comunicação e no âmbito de várias instituições (Marinho, 2005).
Portanto, a dependência química é algo atual para se discutir, uma vez que somente a partir da segunda metade do século passado o conceito de dependência deixou de ser enfocado como um desvio de caráter, ou apenas como um conjunto de sintomas, para ganhar contornos de transtorno mental com características específicas (Ribeiro, 2004).

Além disso, a abordagem exigida para a dependência química é coerente com o modelo psicossocial de saúde em foco na atualidade. Isso porque, tratar a questão do uso abusivo de substâncias psicoativas e a questão da possível dependência que pode emergir em alguns casos, implica discutir não só as questões orgânicas e psicológicas envolvidas, mas também os aspectos sociais, políticos, econômicos, legais e culturais inerentes a esse fenômeno, além das consequências físicas, psíquicas e sociais da mesma (Occhini \& Teixeira, 2006). Portanto, o fenômeno da drogadição é complexo e multifatorial (Cartana, Santos, Fenili \& Spricigo, 2004; Scivoletto, \& Morihisa, 2001).

A compreensão desses aspectos é fundamental para se pensar na questão do tratamento e do cuidado, principalmente no que se refere à eficácia dos mesmos, pois o conhecimento produzido sobre o fenômeno da drogadição não pode estar desvinculado do contexto mais amplo no qual são produzidas as representações que sustentam e organizam a vida social, conferindo sentido às ações humanas.

Em linhas gerais, a dependência de drogas é mundialmente classificada entre os transtornos psiquiátricos, sendo considerada como uma doença crônica que acompanha o indivíduo por toda a sua vida; porém, a mesma pode ser tratada e controlada, reduzindo-se os sintomas, alternando-se, muitas vezes, períodos de controle dos mesmos e de retorno da sintomatologia (Aguilar \& Pillon, 2005; Leite, 2000).

A OMS (2001) destaca ainda, que a dependência química deve ser tratada simultaneamente como uma doença médica crônica e como um problema social. Pode ser caracterizada como um estado mental e, muitas vezes, físico que resulta da interação entre um organismo vivo e uma droga, gerando uma compulsão por tomar a substância e experimentar seu efeito psíquico e, às vezes, evitar o desconforto provocado por sua ausência. Não basta, portanto, identificar e tratar os sintomas, mas sim, identificar as consequências e os motivos que levaram à mesma, pensando o indivíduo em sua totalidade, para que se possa oferecer outros referenciais e subsídios que gerem mudanças de comportamento em relação à questão da droga.

Além da necessidade de buscar constantemente a droga, a dependência causa mudanças acentuadas na interação do indivíduo com seus familiares, afetando suas relações sociais e até mesmo profissionais. Segundo o Manual Diagnóstico e Estatístico de Transtornos Mentais - DSM-IV, publicado pela Associação Psiquiátrica Americana (2000), a característica primordial da dependência de substâncias corresponde à presença de um conjunto de sintomas cognitivos, comportamentais e fisiológicos, que evidencia que o indivíduo continua a utilizar uma determinada substância, apesar dos problemas significativos relacionados à mesma - tanto em termos de saúde quanto pessoais e sociais. Sendo assim, existe um padrão de auto-administração repetida, o qual geralmente resulta em tolerância, abstinência e comportamento compulsivo de consumo da droga. 
Silveira Filho (1995) acrescenta ainda, que para esses indivíduos a droga passou a exercer um papel central na suas vidas, na medida em que, por meio do prazer, ela preenche lacunas importantes, tornando-se indispensável para o funcionamento psíquico dos mesmos.

O diagnóstico de uma dependência química exige a avaliação de diversos aspectos, uma vez que os padrões de consumo de drogas na atualidade são diversificados, sendo a dependência o último estágio. Além disso, o tratamento da drogadição é algo prolongado. Entretanto, romper o ciclo de dependência é algo muito difícil e delicado, pois os indivíduos que se tornam dependentes vivenciam um sofrimento físico e psíquico intensos, tendo sua vida afetada, bem como suas famílias, amigos e a comunidade de uma forma geral.

Atualmente existem diversos profissionais implicados no atendimento à dependência química, porém, o Brasil não possui uma legislação definindo o papel de cada profissional no que diz respeito ao tratamento da mesma (Ribeiro, 2004). Além disso, os profissionais que lidam com essa questão hoje não possuem uma formação particular sobre o tema, uma vez que os cursos de graduação, muitas vezes, não apresentam opções nesse sentido (Ochini \& Teixeira, 2006).

Portanto, discutir e cuidar da dependência química na atualidade é encará-la dentro do modelo biopsicossocial de saúde, considerando o paciente em sua totalidade, encarando-o como um ser ativo no processo saúde/doença. Assim, segundo Leite (2000) o tratamento da dependência química deve abranger o indivíduo, bem como o impacto e as consequências do consumo sobre as diversas áreas da vida do mesmo.

\section{Promoção e Prevenção na Dependência Química: Uma Realidade de acordo com o Novo Paradigma de Saúde}

A dependência química, como um grave problema de saúde pública, necessita de atenção especial. Portanto, a área de saúde tem muito a realizar no que diz respeito ao uso de drogas e à promoção de saúde (Gelbcke \& Padilha, 2004). Assim, trabalhar essa questão na nossa realidade exige um conjunto de ações específicas que envolvam melhorias tanto no tratamento em si, no caso da dependência já instalada, quanto em termos de promoção e prevenção ao uso de drogas, de acordo com o modelo biopsicossocial de saúde, o qual apresenta uma concepção holística do ser humano.

Dentro desses parâmetros, considerando-se as características e os fatores relacionados ao uso de drogas na atualidade, a condução de um programa terapêutico para o indivíduo dependente exige uma avaliação individual, uma vez que não existe um modelo que seja adequado para todos os pacientes. Atualmente, diversos tipos de tratamento estão sendo implantados para o trabalho com a dependência química, como por exemplo, o tratamento médico, o comportamental, o psicoterápico, o psiquiátrico ou o da ajuda mútua. Esses tipos de tratamentos implicam em intervenções terapêuticas específicas, a saber: desintoxicação (considerado apenas o primeiro passo), farmacoterapia, psicoterapias (individual, em grupo e com os familiares), terapias (ocupacional e cognitivo-comportamental), além dos grupos de ajuda mútua (Macieira, 2000).

É necessário pontuar que o atendimento a dependentes químicos envolve dois aspectos centrais: primeiro, a desintoxicação com a finalidade de retirada da droga e seus efeitos, e segundo, a manutenção, ou seja, a reorganização da vida do indivíduo sem o uso da droga (Macieira, 2000). Estudos apontam que, ainda hoje, observam-se baixos índices de sucesso no tratamento da drogadição, pois diversos fatores podem contribuir para a não adesão ao tratamento, o abandono ou, até mesmo, para o uso de substâncias psicoativas durante o mesmo (Aguilar \& Pillon, 2005).

Entretanto, segundo Ferreira e Luis (2004), é de suma importância destacar que a realidade brasileira nunca teve uma política específica de saúde, em nível nacional, a respeito da questão das drogas, o que começou a mudar a partir de 1988 quando foram definidos os requisitos para a criação dos Centros Regionais de Referência em Prevenção e Tratamento ao uso abusivo de drogas, sejam estas lícitas ou ilícitas.

Com a Declaração de Caracas, em 1990, vinculou-se a atenção psiquiátrica à atenção primária em saúde. Com a reforma psiquiátrica, foram estabelecidas novas diretrizes para a assistência em saúde mental, definindo as normas a serem seguidas para a implantação dos chamados Núcleos/ Centros de Atenção Psicossocial (NAPS/CAPS). Assim, segundo Ferreira e Luis (2004), em um primeiro momento, os casos de intoxicação/abstinência em relação ao uso de drogas eram encaminhados para os mesmos, porém estes não atendiam todas as necessidades dos usuários.

A partir de 2002, em função dessa realidade e do aumento significativo do uso de substâncias psicoativas e de suas consequências associadas, o Ministério da Saúde instituiu o Programa Nacional de Atenção Integrada ao usuário de Álcool e outras Drogas, demonstrando uma vontade política direcionada à criação de serviços específicos para usuários e dependentes químicos, considerando-se as particularidades dessa problemática, o que não foi e ainda não está sendo fácil para implantar e sustentar (Ferreira \& Luis 2004).

Pode-se dizer, então, que a forma de encarar a dependência química, e trabalhar com a mesma, sofreu alterações, principalmente no final do século XX, buscando-se uma abordagem mais ampla e coerente do usuário ou do dependente químico, uma vez que, até então, a dependência estava diretamente relacionada à assistência psiquiátrica.

A necessidade de encarar a questão da dependência química como uma realidade diferenciada e que necessita de acompanhamento - não sendo, portanto, uma questão apenas de moral ou de caráter do indivíduo -, traz à tona a importância de se discutir ações de promoção e de prevenção ao uso de drogas, com a finalidade de reduzir esse fenômeno em nossa realidade.

Atualmente, em função da expansão do consumo de substâncias psicoativas e dos problemas a ele associados, muito se tem falado a respeito da prevenção, estratégia considerada de suma importância para se trabalhar o fenômeno da drogadição. Alguns autores (e.g., Marinho, 2005), entretanto, pontuam que muitas vezes, a questão do consumo fica envolvida em significações marginais que acabam gerando e reforçando preconceitos e segregação em relação ao usuário, 
ao invés de propiciar uma sensibilização para a mudança de comportamento.

Assim, a realidade vivenciada mostra a necessidade de se trabalhar em um nível anterior, ou seja, na promoção da saúde visando, segundo Gelbcker e Padilha (2004), a questão de estilos de vida e de educação para a saúde, a qual pode ser encarada como uma estratégia política e educacional adotada por muitos governos com o propósito de garantir a equidade. Segundo esses autores, a promoção da saúde envolve aspectos como capacitar, educar, buscar a paz, respeitar os direitos humanos, justiça social, equidade no atendimento. Dessa maneira, promovendo a saúde podese reduzir o fenômeno das drogas na nossa realidade, uma vez que promover a saúde é uma postura que está de acordo com o novo modelo de saúde, o qual considera o indivíduo na sua totalidade.

Refletindo sobre as características da promoção da saúde, pode-se dizer que as estratégias utilizadas devem visar a transformação das situações de desigualdade, além de instrumentalizar o indivíduo com informações, levando-o a se sentir parte importante do contexto em que vive, dando condições e capacitando-o para que ele tenha uma vida saudável. Esses elementos são fundamentais para que o mesmo tenha melhores condições de avaliar e discernir aspectos relacionados à questão da droga, podendo evitar o seu uso.

Para que isso aconteça efetivamente, é necessário o envolvimento de diversos grupos na sociedade, principalmente a família, uma vez que esta apresenta um papel crucial no processo de desenvolvimento de seus membros, constituindose como o primeiro agente educativo/preventivo. Por meio da família a criança vai aprender condutas, hábitos, valores, observando as atitudes dos pais frente à vida e aos problemas inerentes ao cotidiano (Carranza \& Pedrão, 2005).

Além disso, a família necessita ter condições básicas de sobrevivência para garantir o desenvolvimento integral de seus membros. Isso tornaria possível maximizar os fatores de proteção ao uso de drogas presentes na família e minimizar a influência dos fatores de risco desse ambiente, permitindo ao indivíduo desenvolver um rol de habilidades para lidar com situações de pressão, de medo e de perda no seu cotidiano. É claro que o desenvolvimento dessas habilidades não depende única e exclusivamente da família, porém a mesma tem um papel preventivo relevante, bem como um papel significativo na adesão ao tratamento quando existe uma dependência já diagnosticada.

Entretanto, vale ressaltar que muitas estratégias adotadas, em termos de promoção e de prevenção em relação ao uso de drogas, apresentam uma influência do método cartesiano. A proposta da promoção da saúde é ampla e visa a integridade do indivíduo. Porém, muitos projetos educacionais na área de saúde partem do pressuposto que se pode educar para a saúde, fato que levou a veiculação do ideal de que a assimilação do saber instituído leva à aquisição de novos comportamentos, tornando a educação normativa. Ou seja, alguém, além do próprio indivíduo, conhece o que é melhor para ele e para todos que estão ao seu redor. Isso corresponde a uma herança clara do método cartesiano que ainda prevalece nas áreas de saúde e de educação desde o surgimento da modernidade (Gazzinelli, Gazzinelli, Reis \& Penna, 2005).
Para que essa visão se altere, e realmente ocorra a promoção da saúde, há a necessidade de se romper com o padrão cientificista, buscando pensar a educação para saúde em termos mais abrangentes, que considerem o indivíduo em sua totalidade, o qual possui uma subjetividade, bem como valores e saberes diferentes daqueles com os quais os profissionais de saúde e educação lidam. Há, portanto, uma necessidade de aprendizagem dos dois lados (Gazzinelli, Gazzinelli, Reis \& Penna, 2005).

Assim, no caso da dependência química, é necessário considerar e buscar entender qual o significado na mesma na vida de cada indivíduo, uma vez que as histórias de vida são diferenciadas. Além disso, cada um possui formas específicas de representar o processo de saúde e doença, o que implica em olhar para a subjetividade inerente nessa situação, vislumbrando, também, os sentimentos, desejos, as necessidades desse indivíduo, o qual necessita ser encarado como um ser ativo no processo saúde/doença, exigência do novo paradigma de saúde na atualidade.

\section{Considerações Finais}

A partir da reflexão acima apresentada, é possível concluir que discutir a dependência química na atualidade é discutir a questão do processo saúde/doença, tanto em termos conceituais, de formação e de atuação dos profissionais na área de saúde, quanto no que se refere à questão do tratamento e da promoção da saúde.

Os conceitos de saúde e doença, bem como a questão do uso de substâncias psicoativas, sofrem uma influência direta do contexto histórico, cultural e social, o que pode ser verificado analisando-se os principais aspectos da evolução do homem, desde a Antiguidade até hoje, uma vez que essas questões sempre permearam a vida humana.

Entretanto, a partir do século XX, são constatadas transformações no que diz respeito ao processo saúde/doença, sendo que o uso de substâncias psicoativas assumiu proporções alarmantes, tornando-se um complexo problema em termos de saúde pública, o qual exige a definição de intervenções particulares. Porém, falar do uso de drogas não é falar apenas de uma questão biológica, é falar de um indivíduo integral, para o qual as drogas possuem uma representação específica.

Portanto, o tratamento da dependência química na atualidade, bem como as intervenções visando a promoção da saúde e a prevenção do uso de drogas, devem romper com o modelo cartesiano, apesar das dificuldades ainda vivenciadas, e assumir que reduzir o fenômeno da drogadição em nossa realidade é algo que depende da interação entre vários grupos, exigindo mudanças substanciais na organização social, diminuindo drasticamente as desigualdades presentes nesse contexto. Também são necessárias mudanças na formação dos profissionais que lidam com essa questão, além de alterações na forma de encarar o paciente ou o indivíduo que apresenta maior vulnerabilidade em relação à droga, encarando os mesmos como seres ativos, que possuem saberes e fazeres próprios, diretamente implicados no processo saúde/doença. 


\section{Referências}

Associação Psiquiátrica Americana (2000). Manual diagnóstico e estatístico de transtornos mentais - DSM-IV (4 ${ }^{\mathrm{a}}$ ed.) (D. Batista, Trad.). Porto Alegre: Artes Médicas.

Aguilar, L. R., \& Pillon, S. C. (2005). Percepción de tentaciones de uso de drogas en personas que reciben tratamiento. Revista Latino-Americana de Enfermagem, 13, 790-797.

Ayres, J. R. C. M. (2001). Sujeito, intersubjetividade e práticas de saúde. Ciência e Saúde Coletiva, 6, 63-72.

Backes, D., Lunardi, V., \& Lunardi Filho, W. D. (2006). A humanização hospitalar como expressão da ética. Revista LatinoAmericana de Enfermagem, 14, 132-135.

Bucher, R (1992). Drogas e drogadição no Brasil. Porto Alegre: Artes Médicas.

Cairus, H. F., \& Ribeiro Jr, W. A. (2005). Textos hipocráticos: o doente, o médico e a doença. Rio de Janeiro: Editora Fiocruz.

Canoletti, B., \& Soares, C. B. (2005). Programas de prevenção ao consumo de drogas no Brasil: uma análise da produção científica de 1991 a 2001. Interface - Comunicação, Saúde e Educação, 9, 115-129.

Capra, F. (1982). O ponto de mutação. São Paulo: Cultrix.

Caprara, A. (2003). Uma abordagem hermenêutica da relação saúde-doença. Cadernos de Saúde Pública, 19, 923-931.

Carranza, D. V. V., \& Pedrão, L. J. (2005). Satisfacción personal del adolescente adicto a drogas em el ambiente familiar durante la fase de tratamiento em um instituto de salud mental. Revista Latino-Americana de Enfermagem, 13, 836-844.

Cartana, M., Santos, S. M. A., Fenili, R. M., \& Spricigo, J. S. (2004). Prevenção do uso de substâncias psicoativas. Texto $e$ Contexto de Enfermagem, 13, 286-289.

Ferreira, P. S., \& Luis, M. A. V. (2004). Percebendo as facilidades e dificuldades na implantação de serviços abertos em álcool e drogas. Texto e Contexto de Enfermagem, 13, 209-216.

Gazzinelli, M. F., Gazzinelli, A., Reis, D. C., \& Penna, C. M. M. (2005). Educação em saúde: conhecimentos, representações sociais e experiências da doença. Cadernos de Saúde Pública, 21, 200-206.

Gelbcke, F. L., \& Padilha, M. I. C. S. (2004). O fenômeno das drogas no contexto da promoção da saúde. Texto e Contexto de Enfermagem, 13, 272-279.

Kalina, E., Kovadloff, S., Roig, P. M., Serran, J. C., \& Cesarman, F. (1999). Drogadição hoje: indivíduo, família e sociedade. Porto Alegre: Artes Médicas.

Leite, M. C. (2000). Aspectos básicos do tratamento da síndrome de dependência de substâncias psicoativas. Brasília: Presidência da República, Gabinete de Segurança Intitucional, Secretaria Nacional Antidrogas.

Macieira, M (2000). Tratamento da dependência química: experiência do PAA-HUCAM-UFES. Em M. A. Luis \& M. A. Santos (Orgs.), Uso e abuso de álcool e drogas: trabalhos apresentados no VI Encontro de Pesquisadores em Saúde Mental e V Encontro de Especialistas em Enfermagem Psiquiátrica (pp. 47-51). Ribeirão Preto: FIERP-EERP-USP/FAPESP.

Macrae, E. (2001). Antropologia: aspectos sociais, culturais e ritualísticos. Em S. Seibel \& A. Toscano Jr. (Eds.), Dependência de drogas (pp. 25-34). São Paulo: Editora Atheneu.
Marinho, M. B. (2005). O demônio nos "paraísos artificiais": considerações sobre as políticas de comunicação para a saúde relacionadas ao consumo de drogas. Interface: Comunicação, Saúde e Educação, 9, 345-354.

Martins, E. R., \& Corrêa, A. K. (2004). Lidar com substâncias psicoativas: o significado para o trabalhador de enfermagem. Revista Latino-Americana de Enfermagem, 12, 398-405.

Mendes, E. V. (1996). Um novo paradigma sanitário: a produção social da saúde. Em E. V. Mendes (Org.), Uma agenda para a saúde (pp. 233-297). São Paulo: Hucitec.

Occhini, M., \& Teixeira, M. (2006). Atendimento a pacientes dependentes de drogas: atuação conjunta do psicólogo e do psiquiatra. Estudos de Psicologia (Natal), 11, 229-236.

Organização Mundial da Saúde (2001). Transtornos devido ao uso de substâncias. Em Organização Pan-Americana da Saúde \& Organização Mundial da Saúde (Orgs.). Relatório sobre a saúde no mundo. Saúde Mental: nova concepção, nova esperança (pp. 58-61). Brasília: Gráfica Brasil.

Ornellas, C. (1999). As doenças e os doentes: a apreensão das práticas médicas no modo de produção capitalista. Revista LatinoAmericana de Enfermagem, 7, 19-26.

Queiroz, M. S. (2003). Saúde e doença: um enfoque antropológico. Bauru: EDUSC.

Queiroz, M. S. (1986). O paradigma mecanicista da medicina ocidental moderna: uma perspectiva antropológica. Revista de Saúde Pública, 20, 309-317.

Rezende, A. L. M. (1986). O processo saúde-doença. Em A. L. M. Rezende (Org.), Saúde e dialética do pensar e do fazer (pp. 85-98) (2 ed). São Paulo: Cortez.

Ribeiro, M. (2004). Organização de serviços para o tratamento da dependência do álcool. Revista Brasileira de Psiquiatria, 26, 50-62.

Rosa, A. S., Cavicchioli, M. G. S., \& Bretãs, A. C. P. (2005). O processo saúde-doença-cuidado e a população em situação de rua. Revista Latino-Americana de Enfermagem, 13, 576-582.

Scivoletto, S., \& Morihisa, R. (2001). Conceitos básicos em dependência química de álcool e outras drogas na adolescência. Jornal Brasileiro de Dependência Química, 2, 30-33.

Sevalho, G. (1993). Uma abordagem histórica das representações sociais de saúde e doença. Cadernos de Saúde Pública, 9, 349363.

Silveira Filho, D. (1995). Drogas: uma compreensão psicodinâmica das farmacodependências. São Paulo: Casa do Psicólogo.

Toscano Jr., A. (2001). Um breve histórico sobre o uso de drogas. Em S. Seibel \& A. Toscano Jr. (Eds.). Dependência de drogas (pp. 7-23). São Paulo: Atheneu.

Recebido em 12.02 .08

Primeira decisão editorial em 19.11.08

Versão final em 19.12.08

Aceito em 17.04.09 